\title{
In vitro comparison of surgical techniques in times of the SARS-CoV-2 pandemic: electrocautery generates more droplets and aerosol than laser surgery or drilling
}

\author{
Daniela B. Guderian ${ }^{1} \cdot$ Andreas G. Loth ${ }^{1} \cdot$ Roxanne Wei $^{1} \cdot$ Marc Diensthuber $^{1} \cdot$ Timo Stöver $^{1} \cdot$ Martin Leinung $^{1} \mathbb{D}$
}

Received: 9 July 2020 / Accepted: 28 August 2020 / Published online: 7 September 2020

(c) Springer-Verlag GmbH Germany, part of Springer Nature 2020

\begin{abstract}
Introduction Based on current knowledge, the SARS-CoV-2 is transmitted via droplet, aerosols and smear infection. Due to a confirmed high virus load in the upper respiratory tract of COVID-19 patients, there is a potential risk of infection for health care professionals when performing surgical procedures in this area. The aim of this study was the semi-quantitative comparison of ENT-typical interventions in the head and neck area with regard to particle and aerosol generation. These data can potentially contribute to a better risk assessment of aerogenic SARS-CoV-2-transmission caused by medical procedures. Materials and methods As a model, a test chamber was created to examine various typical surgical interventions on porcine soft and hard tissues. Simultaneously, particle and aerosol release were recorded and semi-quantitatively evaluated timedependently. Five typical surgical intervention techniques (mechanical stress with a passive instrument with and without suction, $\mathrm{CO}_{2}$ laser treatment, drilling and bipolar electrocoagulation) were examined and compared regarding resulting particle release.

Results Neither aerosols nor particles could be detected during mechanical manipulation with and without suction. The use of laser technique showed considerable formation of aerosol. During drilling, mainly solid tissue particles were scattered into the environment $\left(18.2 \pm 15.7\right.$ particles $\left./ \mathrm{cm}^{2} / \mathrm{min}\right)$. The strongest particle release was determined during electrocoagulation $\left(77.2 \pm 30.4\right.$ particles $\left./ \mathrm{cm}^{2} / \mathrm{min}\right)$. The difference in particle release between electrocoagulation and drilling was significant $(p<0.05)$, while particle diameter was comparable. In addition, relevant amounts of aerosol were released during electrocoagulation (79.6\% of the maximum flue gas emission during laser treatment).

Discussion Our results demonstrated clear differences comparing surgical model interventions. In contrast to sole mechanical stress with passive instruments, all active instruments (laser, drilling and electrocoagulation) released particles and aerosols. Assuming that particle and aerosol exposure is clinically correlated to the risk of SARS-CoV-2-transmission from the patient to the physician, a potential risk for health care professionals for infection cannot be excluded. Especially electrocautery is frequently used for emergency treatment, e.g., nose bleeding. The use of this technique may, therefore, be considered particularly critical in potentially infectious patients. Alternative methods may be given preference and personal protective equipment should be used consequently.
\end{abstract}

Keywords SARS-CoV-2 $\cdot$ Airborne infection $\cdot$ Aerosol $\cdot$ Particle

\section{Introduction}

The SARS-CoV-2 pandemic is affecting people's lives and working environments worldwide and poses major challenges for health systems in particular [1]. The

Martin Leinung

martin.leinung@kgu.de

1 Department of Otolaryngology, Head and Neck Surgery, University Hospital Frankfurt, Theodor-Stern-Kai 7, 60590 Frankfurt, Germany course of the disease is not yet fully understood, but varies from asymptomatic courses to severe pneumonia with life-threatening organ failure [2, 3]. In addition to the containment of the pandemic and the treatment of patients suffering from COVID-19, protection of health 
care professionals is a priority to ensure the operational readiness of the medical system. At present, droplet and smear infection through coughing and sneezing, as well as transmission through aerosols (droplets smaller than $5 \mu \mathrm{m}$ [4]), is considered to be the main transmission route for this disease. SARS-CoV-2-positive patients present high virus densities in the upper and lower respiratory tract $[5$, 6]. At expiration [7] and speaking [8] virus containing aerosols are released $[9,10]$. ENT physicians are exposed to SARS-CoV-2 due to their direct proximity to the upper airways during examination and treatment.

In addition, medical interventions in the area of the mucous membranes of the upper airways could promote the formation of aerosols and thus facilitate the transmission of pathogens. For otorhinolaryngology, this applies to interventions with passive instruments as well as active instruments such as electrocoagulation, laser or drills. Up today, only few studies have examined the aerosol generation and distribution during specific ENT medical interventions. A previously described model used fluorescein dye for detection of particle distribution in mastoidectomy and sinus surgery [11-13]. However, this method was mainly used to detect the spread of droplets and to a lesser extent the formation of aerosols, which are particularly relevant in the context of the COVID-19 pandemic.

The aim of the presented study was therefore to develop an experimental setup for the simultaneous assessment of aerosol and particle formation in various typical ENT interventions. Furthermore, a semi-quantitative comparison of these interventions was performed. These data are the basis for a risk assessment for potential aerogenic SARS-CoV-2 transmission and lead to recommendations for typical ENT interventions.

\section{Materials and methods}

\section{Experimental setup}

The setup developed to carry out the experiments is shown in Fig. 1. The interventions were performed in a test chamber (1). An opening at the front wall of the chamber (2) allowed experimental interventions on the specimen (3). An acrylic glass plate on the rear wall of the chamber with a distance of $4 \mathrm{~cm}$ to the tissue sample was used for particle detection (4). Splashes of liquid and tissue particles released by the surgical intervention technique adhered to the plate. These splashes were recorded with a digital optical microscope (VHX5000, Keyence, Japan) for semi-quantitative evaluation. The acrylic glass plate was replaced for each test run. To detect the experimental aerosol formation, a black and white test picture (6) was documented by a Full-HD video camera (EOS 500, Canon, Japan) through a window (5) in the upper part of the chamber. Aerosol release was quantitatively assessed by the turbidity of the sight on the text picture (see below for details on the methodology of particle and aerosol measurement).

Experiments were performed on fresh porcine hard and soft tissue specimens (bone and muscle). To facilitate the evaluation of particle formation, the tissue samples were immersed in royal blue ink and $1 \%$ methylene blue for $12 \mathrm{~h}$ and hereby stained intensely blue.

\section{Experimental conditions}

Five different interventions were evaluated:

1. Mechanical stress without suction: (double elevator according to Freer, sharp side, model 488,074, KARL STORZ SE \& Co. KG, Tuttlingen, Germany).

2. Mechanical stress with suction: (nasal aspirator according to Ferguson).
Fig. 1 Representation of the sample chamber (1) with an opening (2) for processing the sample material (3). Ejected particles are collected on the slide (4) on the rear wall for later microscopic analysis. In the upper part of the sample chamber the aerosol formation is video-documented through an observation tube (5). Here the haze of the view of a target object (6) is evaluated

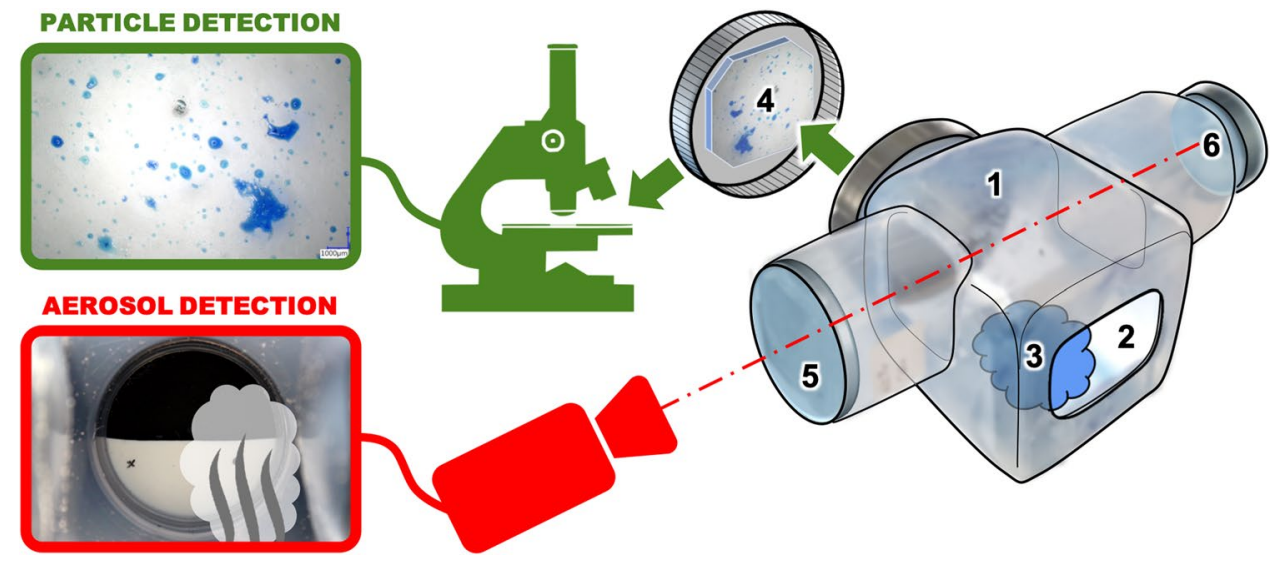


3. Laser treatment: $\left(\mathrm{CO}_{2}\right.$ laser AcuPulseTM DUO, Lumenis company, Israel). Selected settings: $3.5 \mathrm{~W}$, micromanipulator-guided, continuous power output, spot beam focused on the tissue surface without scanner.

4. Drilling: (Osseoduo, Bien-Air, Switzerland. milling cutter: $3.5 \mathrm{~mm}$ cutting drill, 40,000 rpm).

5. Electrocoagulation: $\left(\mathrm{VIO}^{\circledR} 200 \mathrm{~S}\right.$, Erbe Elektromedizin $\mathrm{GmbH}$, Germany, $60 \mathrm{~W}$ at power level 6, bipolar mode).

The tissue specimens were treated for $3 \mathrm{~min}$ in each test condition. The experimental intervention was interrupted after 1, 2 and $3 \mathrm{~min}$ to record the particle formation. Then the intervention was resumed. The video documentation to record the aerosol formation was done continuously. To eliminate inter- and intraobserver variability, measurements were performed fully automatic with different computerbased algorithms described below. The method of particle measurement via counting have been widely used to assess aerosol creation [11-13]. Turbidity measurements are more commonly used in larger scale pollution measurements but were adapted to show aerosol generation in another way [14].

\section{Particle measurement}

The acrylic glass plate on the rear wall of the sample chamber was photodocumented with a digital microscope (VHX 5000, Keyence, Japan) at 4 predefined positions $(20 \times$ magnification $)$. These images were subsequently post-processed using proprietary software based on LabView 2011 (National Instruments, USA) (see Fig. 2). A grey threshold-based segmentation was performed on a color plane extraction of the original image with good contrast of the originally blue stained tissue particles. The detected particles were evaluated with regard to their number and size (max. diameter).

\section{Aerosol measurement}

During manipulation of the specimen, a video file of the target object (no. 6 in Fig. 1) was recorded with a Full-HD camera at 25 frames per second. The resulting video was then post-processed frame by frame, also using proprietary software. Indicator points were randomly distributed over the surface of the target object (see Fig. 2). After averaging, the gray values were determined per image at these positions, resulting in a data graph with a time resolution of $40 \mathrm{~ms}$. The measured turbidity of the camera view is an indirect measure for the aerosol density in the sample chamber.

\section{Statistics}

Statistical evaluation was carried out using Microsoft Excel (Excel for Mac, version 16.16.20, Microsoft, USA). Non-parametric test procedures (Wilcoxon rank sum test for comparisons within a test condition, Mann Whitney $U$ test for comparisons between test conditions) were used due to the lack of detectability of a normal distribution.
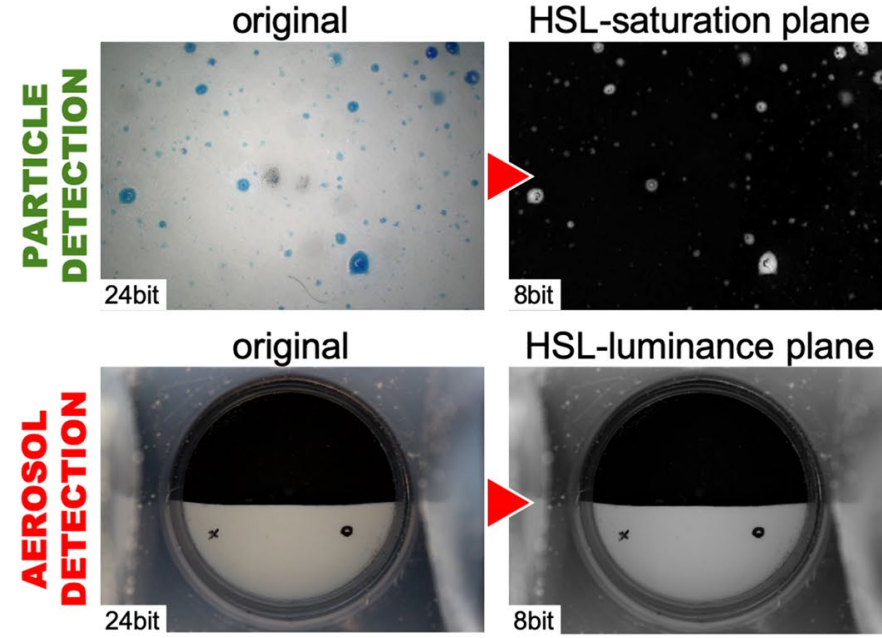

8 bit
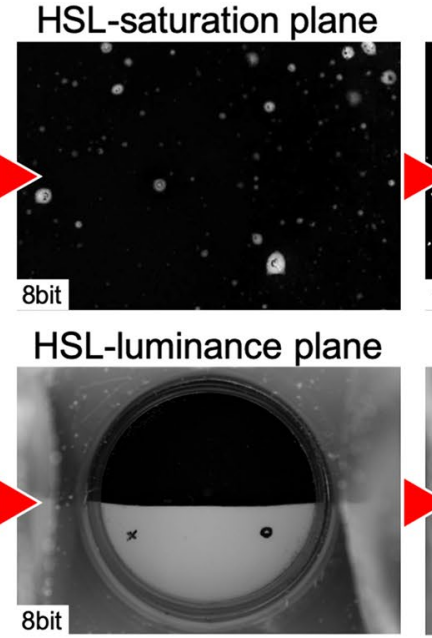

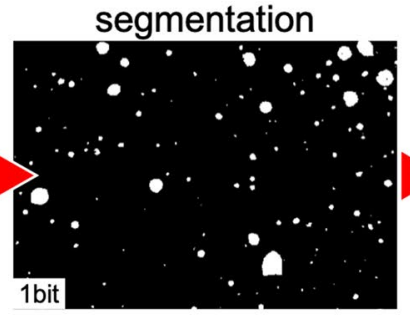

indicator points

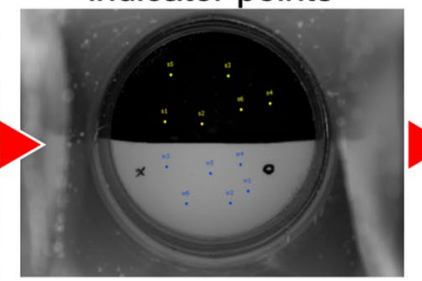

particle analysis

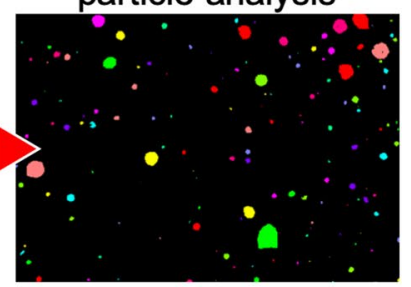

grey values

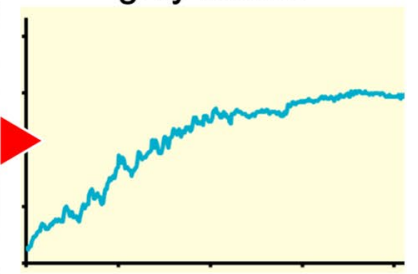

Fig. 2 Procedure for particle and aerosol analysis: For particle detection, the blue splashes should be quantified in the original image (top left). For this purpose, a segmentation is performed on a color plane extraction and the areas and maximum diameters of each particle are counted. Another color plane extraction of the original image is also used for the analysis of aerosol formation. At different indicator positions the grey values are determined over all single images of the video recording. The resulting graph represents the degree of aerosol formation at a given time 


\section{Results}

Our results demonstrated clear differences comparing surgical intervention techniques. With the described experimental setup, all five test conditions could be assessed regarding their application-specific aerosol and particle generation.

\section{Intervention 1 (mechanical stress without suction)}

In the case of mechanical stress with a passive instrument, no particle or aerosol formation was detected even after several minutes of intensive manipulation of the tissue (see Fig. 3, first line).

\section{Intervention $\mathbf{2}$ (mechanical stress with suction)}

Similarly, no particle or aerosol formation was detected during mechanical impact by use of a passive instrument in direct tissue contact with additional suction (cf. Fig. 3, second line).
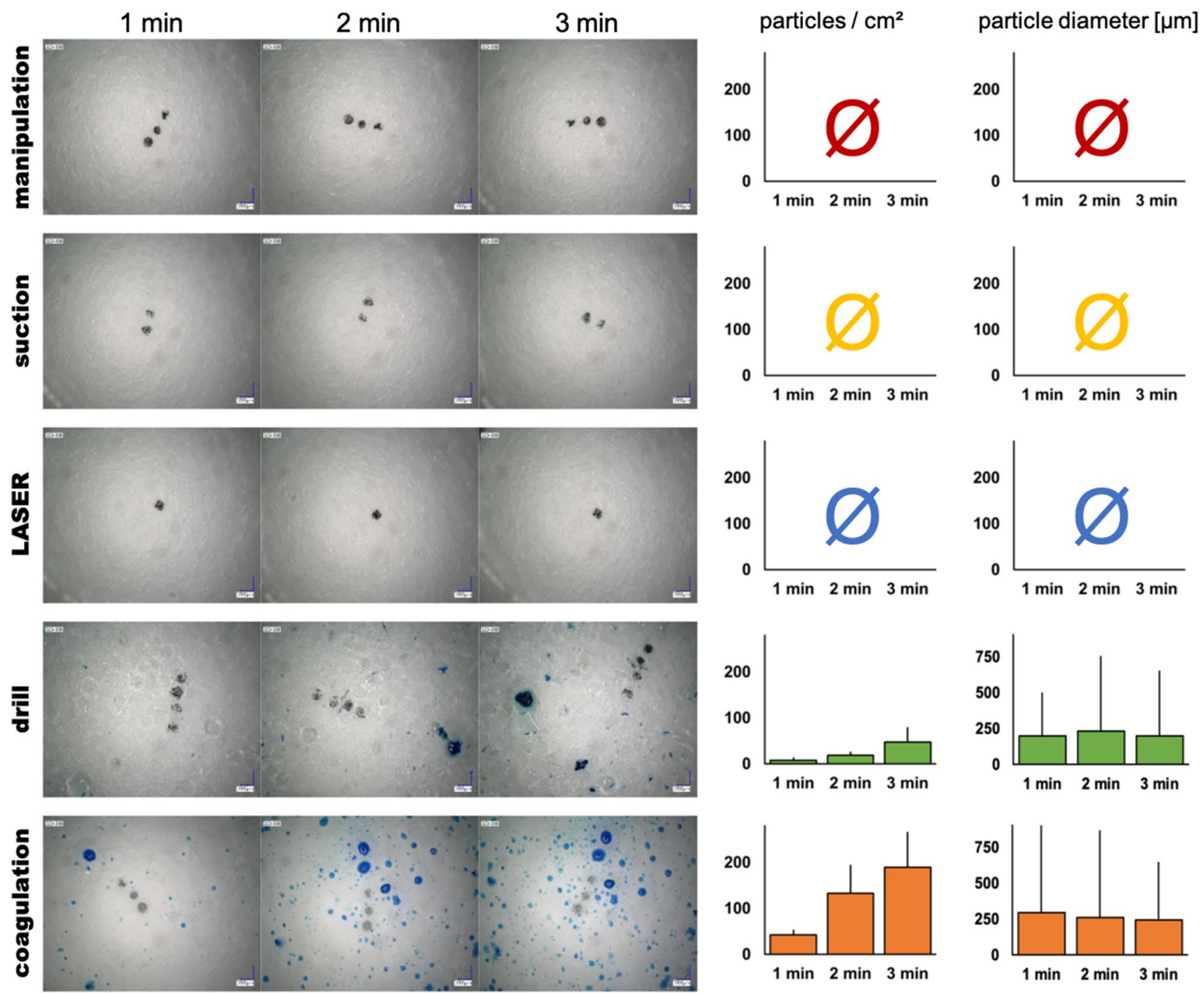

Fig. 3 Evaluation of particle formation: during mechanical manipulation, suction in tissue contact or laser application, no detectable particle formation occurred even after several minutes of treatment. During drilling, the slide is covered with a lot of rinsing liquid, but only a small amount of tissue particles are thrown along. There is a slight increase over time. With electrocoagulation the particle formation is much more pronounced. The mean particle size during drilling and coagulation shows no significant difference with a large variance in particle diameter. The black dots in the microscopic images are markings for finding the respective positions again and are not included in the particle evaluation 


\section{Intervention 3 (laser treatment)}

The laser treatment of the tissue did not lead to a detectable particle formation at any of the three points in time of the analysis (see Fig. 3, third line). Under the surgical microscope, however, a highly directed ejection of very fine droplets was observed. These droplets were ejected away from the tissue almost exclusively in the direction of the incoming laser beam. The $\mathrm{CO}_{2}$ laser application led to a strong aerosol formation (lower series of images and blue curve in Fig. 4): Within only $3 \mathrm{~s}$ the view of the test picture was obfuscated by $60 \%$. After a further $9 \mathrm{~s}$ the maximum value was reached. Additionally, rising plumes of smoke at the beginning of the intervention were created by the laser (Fig. 4). Over the course of the treatment, the test chamber was filled completely with smoke gas and homogeneous fog of increasing density. This caused the scattering of the measured values to decrease over time.

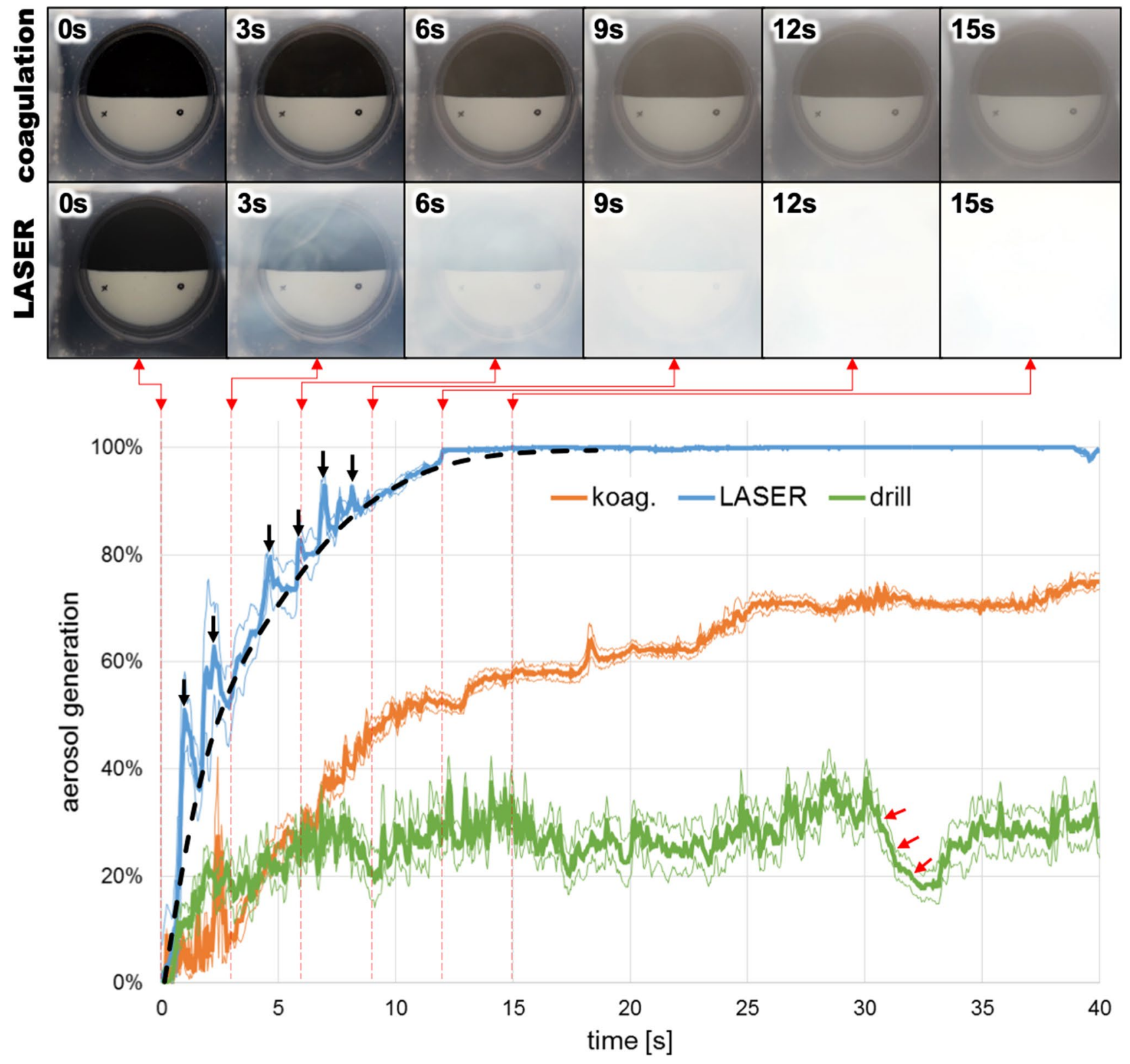

Fig. 4 Evaluation of aerosol formation: The faster and more intensive aerosol formation by the laser compared to electrocauterization is clearly visible in the direct comparison of the individual images. The spikes in the graph beyond the dotted trend line (black arrow markings) are caused by rising plumes of smoke at the beginning of the laser treatment. Nebulisation during drilling is not caused by flue gas, but by spraying the finest droplets of the rinsing liquid. The rapid sinking of the fog during a short drilling pause (red arrows) is clearly visible; aerosol from coagulation or laser would be in the air until the sample chamber is sucked out or aired 


\section{Intervention 4 (drilling)}

Processing the specimens with a cutting drill resulted in clearly detectable particles. The released particles increased with additional processing time up to a density of $47.2 \pm 31.8$ particles $/ \mathrm{cm}^{2}$ after 3 min of treatment (mean value \pm standard deviation). This corresponded to a rate of $18.2 \pm 15.7$ particles $/ \mathrm{cm}^{2} / \mathrm{min}$ at a distance of $4 \mathrm{~cm}$ from the tissue. The average size of the particles remained constant over the experimental time $(208.6 \pm 17.1 \mu \mathrm{m})$. The particles consisted of solid tissue. In addition, a light precipitation of clear irrigation fluid appeared on the acrylic glass plate. With increasing processing time these droplets confluated. The detection of the aerosol formation showed a slightly clouded view of the target object, which, however, quickly cleared up during a short intervention pause (red arrows in Fig. 4 at $t=31 \mathrm{~s}$ ). This effect represented a spray mist rather than a gaseous aerosol.

\section{Intervention 5 (electrocoagulation)}

After electrocoagulation, $189.1 \pm 76.8$ particles $/ \mathrm{cm}^{2}$ were detected after 3 min of intervention. The particles were mostly intensive and homogeneous blue stained droplets. Solid tissue parts were found only sporadically. With $77.2 \pm 30.4 \mathrm{particles} / \mathrm{cm}^{2} / \mathrm{min}$ electrocoagulation created 4.2 times more particles than drilling intervention. This difference was significant $(p<0.05)$. The average particle size for electrocoagulation was $266.2 \pm 25.3 \mu \mathrm{m}$. A significant difference was neither found between the different measuring times, nor in comparison to drilling intervention.

Relevant amount of aerosol was also produced during electrocoagulation (orange curve in Fig. 4). The maximum turbidity was $79.6 \pm 1.2 \%$ and thus significantly lower than the aerosol formation by the laser treatment $(p<0.01)$.

\section{Discussion}

High SARS-CoV-2 densities were previously described in the upper respiratory area, exposing medical staff working in the head and neck area, as ENT physicians, to a particular infectious risk [15]. Surgical interventions such as the insertion of nasal tamponades, the aspiration of secretions from the nose, electrocoagulation of the nasal mucosa during nose bleeding or the use of laser interventions on the nasal mucosa are common ENT procedures. These frequently performed procedure require special consideration and risk analysis. Five typical ENT intervention techniques were examined: mechanical intervention without and with simultaneous suction, laser intervention, the use of a drilling system and bipolar electrocoagulation. Increased formation of particles and/or aerosols was considered as an indication of tissue or tissue components spreading and thus as an indicator of the potential risk of intervention-related infection.

\section{Mechanical stress without suction}

No droplet or aerosol formation could be detected during mechanical stress, which was simulated by scratching with a sharp dissector. This observation is consistent with the results of other authors [11]. Our data indicate a comparatively low risk of aerosol formation, thus presumably low virus distribution and potentially low infection risk associated with this procedure. A typical clinical situation may be seen during insertion or removal of nasal tamponades. However, as we only used a model setup, the real live clinical situation may be different: In an awake patient, nasal interventions may result in additional effects as aerosol formation due to reflective sneezing or coughing [16].

\section{Mechanical stress with suction}

No formation of aerosols or droplets was observed during mechanical stress with suction. Postoperative suctioning of the main nasal cavities is an example of a very common ENT procedure in postoperative nasal care or in the treatment of nasal bleeding. The results obtained from our model suggest that this intervention is not associated with relevant aerosol formation. No addition aerosol or particles were detected with simultaneous suction. Furthermore, Sharma et al. were able to demonstrate a protective effect of suction in their study on cadaver heads, as the aerosol formation was significantly reduced [12]. Even with excessive tissue destruction using a microdebrider, the integrated suction effectively prevented droplet formation [11]. Although our data did not show a positive effect of the application of a suction device due to the experimental design, it seems obvious that additional suction may be considered in mechanical nasal interventions.

\section{Laser treatment}

No particle formation was detected in tissue treatment with a $\mathrm{CO}_{2}$ laser. However, an emission of very fine droplets was observed under the surgical microscope. Since the plate for particles was mounted in the opposite direction in our experimental setup, this minimal particle formation could not be detected. The laser-induced aerosol formation, however, was considerable and surpassed all other surgical intervention techniques. In ENT medicine, lasers are widely used for various clinical applications. The $\mathrm{CO}_{2}$ laser in our study is a commonly used laser system. Depending on the applied power density, thermal tissue effects range from coagulation, carbonization (charring of the tissue) to vaporization [17]. All these effects could also be shown in our experiment. 
It is known from laser treatment in HPV-associated papilloma that HPV-DNA can be detected in the resulting flue gas $[18,19]$. Thus, increased rates of HPV infections among surgical staff $[20,21]$ have been discussed [22]. Our data clearly confirm an excessive aerosol release during laser application. In the interest of employee protection adequate suction and FFP3 protective masks should be recommended when applying laser technology in SARS-CoV-2 patients.

\section{Drilling}

Although the use of a drilling system showed less particle formation compared to electrocoagulation, complete pieces of tissue were released and distributed in our study. The dispersion of tissue particles during drilling was also observed previously in cadaver studies at the frontal and lateral skull base $[11,13]$. Depending on the viral load in these tissues, these particles have to be considered as potentially infectious (see Table 1).

As far as microscopically assessable, in our study the aerosol created by drilling consisted of clear droplets of the irrigation fluid without visible solid tissue components. Other studies indicated, that even spray mist created by a drilling system and transferred over a distance of several meters was contaminated with blood particles of the patient [23]. Thus, we cannot exclude that the apparently "clean" spray mist detected in our study could also contain biological material and could be infectious for SARS-CoV-2.

\section{Bipolar electrocoagulation}

Intervention with electrocoagulation revealed a considerable aerosol formation, even though the density of the flue gas did not reach the same level as with laser treatment. With regard to particle formation, electrocoagulation showed the strongest effect in comparison to all other intervention techniques. In contrast to the application of the drilling system; however, these particles did not consist of solid pieces of tissue, but of liquid drops. In addition, with electrocoagulation these liquid drops were colored deep blue (from prepared blue-dyed

Table 1 Comparison of aerosol and particle formation by different treatment techniques

\begin{tabular}{|c|c|c|}
\hline Impact & Particle generation & Aerosol generation \\
\hline $\begin{array}{l}\text { Mechanical } \\
\text { manipulation }\end{array}$ & $\varnothing$ & $\varnothing$ \\
\hline Suction & $\varnothing$ & $\varnothing$ \\
\hline Laser & $\varnothing$ & +++ \\
\hline Drill & $\begin{array}{l}+ \\
\left(47.2 \text { part./} / \mathrm{cm}^{2}, p<0.05\right)\end{array}$ & $\varnothing$ (droplets) \\
\hline Coagulation & $\begin{array}{l}+++ \\
\left(189.1 \text { part./} / \mathrm{cm}^{2}, p<0.05\right)\end{array}$ & + \\
\hline
\end{tabular}

tissue). This is an indication for intra- and/or extracellular fluid, that could be associated with a potentially higher risk of pathogen transmission. Similar to the use of a drilling system, the extent of tissue disruption in electrocoagulation is time-dependent: The transfer of tissue and tissue components is linearly related to the duration of application. Our data indicate, that particle formation, thus the risk of infection, may be increased with time exposed to electrocoagulation intervention. For everyday clinical practice, this should result in short time application of electrocoagulation if clinically possible in addition to individual protective measures.

\section{Conclusions for clinical application}

Our data suggest that simple interventions without the use of active instruments carry a comparably low risk of infection, whereas technically supported interventions are associated with exposure to potentially infectious particles and aerosols. Laser applications and drilling are techniques that are more likely to be used in elective procedures. Hence, infectious status of a patient can be determined before intervention. If SARS-CoV2-infection is detected, these intervention techniques should be avoided. In addition, protective measures should be used if applicable [24]. Emergency treatment in cases of uncertain infectious status represents a particular challenge. Bipolar or monopolar coagulation has been frequently used here up to now. The clinical results of electrocautery are favorable [25]. However, against the background of the results obtained in this study, treatment alternatives may be discussed. This includes the use of nasal tamponade alone, if clinically possible. Alternatively, local etching of the mucosa with silver nitrate sticks could also be considered [26]. Primary conservative treatment with hemostyptics and nasal tamponades may also be an alternative treatment. If electrocautery is unavoidable, additional suction most likely reduces particle and aerosol exposure [27]. Regardless of the chosen treatment option, wearing protective glasses is recommended to reduce the risk of conjunctival blood and pathogen transmission [28].

\section{Limitations of the study}

The present study presents a pre-clinical model, which differs from the clinical setting regarding several aspects. Firstly, the particle measurement in our setup was carried out in a test chamber that does not correspond to the spatial dimensions of an oral or nasal cavity. Future studies may look at an anatomic model with naturally shaped nasal and oral cavity, which may differ the spreading of particles and aerosols. Secondly, breathing, which would be airflow directed towards the surgeon, was not simulated in our study. Nevertheless, our setup allowed a reliable detection of differences for typical ENT intervention techniques. 
In our study, aerosol formation was detected indirect via the optical turbidity. Methodically, a maximum value could not be exceeded. Thus, an increase of aerosol formation beyond the maximum value cannot be measured. Despite these limitations, the methodology of our experimental setup was suitable to rank the intervention methods with respect to the amount of particle and aerosol formation.

The extent to which aerosols and particles are generated during laser treatment and cautery depends largely on the basic technical setting chosen. The settings chosen in this study represent the standard used in our hospital. However, these technical settings may vary between institutions and can therefore influence aerosol and particle creation.

We used aerosol and particle detection as a model for potential distribution. Our approach allowed a semi-quantitative classification of particle and aerosol formation. Although we did not use real virus particles our setup is a direct model for aerosols and particles that are clearly related to SARS-CoV-2 infections. Clearly real virus exposure depends on various factors, e.g., individual virus load, not considered in our model. However, our model provides good indirect evidence for aerosol and particle exposure as a risk factor for potential SARS-CoV-2 infection.

\section{Conclusion}

Using an experimental setup, typical ENT interventions on hard and soft tissue were compared semi-quantitatively with regard to particle and aerosol formation. Simple mechanical stress with a passive surgical instrument did not generate any detectable aerosols or particles, whereas the application of a laser and a drill system is associated with a strong material release. Electrocoagulation leads to the highest droplet and aerosol formation. In the light of the current pandemic, we suggest careful use of the above procedures to minimize the possible exposure of medical staff to potentially infectious material. Especially common procedures as electrocoagulation in the emergency treatment of nose bleeding should be viewed critically and adequate measures to reduce aerosol exposure such as PPE and consideration of conservative treatment seem to be appropriate until further data regarding transmission of SARS-CoV-2 is available.

\section{Compliance with ethical standards}

Conflict of interest There are no conflicts of interest to disclose by the authors.

Human and animal rights The submitted manuscript does not report data derived from experimental or clinical observations in human or animal subjects.
Informed consent For the same reason informed consent was neither necessary nor applicable.

\section{References}

1. Zhu N, Zhang D, Wang W et al (2020) A novel coronavirus from patients with pneumonia in China, 2019. N Engl J Med 382(8):727-733. https://doi.org/10.1056/NEJMoa2001017

2. Mackenzie JS, Smith DW (2020) COVID-19: a novel zoonotic disease caused by a coronavirus from China: what we know and what we don't. Microbiol Aust 41:45-50. https://doi.org/10.1071/ MA20013

3. Thomas-Rüddel D, Winning J, Dickmann P et al (2020) „Coronavirus disease 2019“ (COVID-19): update für Anästhesisten und Intensivmediziner März 2020. Der Anaesthesist 69:225-235. https ://doi.org/10.1007/s00101-020-00758-X

4. Seto WH (2015) Airborne transmission and precautions: facts and myths. J Hosp Infect 89:225-228. https://doi.org/10.1016/j. jhin.2014.11.005

5. Zou L, Ruan F, Huang M et al (2020) SARS-CoV-2 viral load in upper respiratory specimens of infected patients. N Engl J Med. 382(12):1177-1179. https://doi.org/10.1056/NEJMc2001737

6. Pan Y, Zhang D, Yang P et al (2020) Viral load of SARS-CoV-2 in clinical samples. Lancet Infect Dis 20(4):411-412. https://doi. org/10.1016/S1473-3099(20)30113-4

7. Chia P, Coleman K, Tan Y et al (2020) Detection of air and surface contamination by severe acute respiratory syndrome coronavirus 2 (SARS-CoV-2) in hospital rooms of infected patients. Emerg Infect Dis 26(7):1583-1591. https://doi.org/10.3201/eid26 07.200885

8. Asadi S, Wexler A, Cappa C et al (2020) (2020) Effect of voicing and articulation manner on aerosol particle emission during human speech. PLoS ONE 15(1):e0227699. https://doi. org/10.1371/journal.pone.0227699

9. Santarpia J, Rivera D, Herrera V, et al. (2020) Transmission potential of SARS-CoV-2 in viral shedding observed at the University of Nebraska Medical Center, medRxiv 2020.03.23.20039446. https://doi.org/10.1101/2020.03.23.20039446

10. Liu Y, Ning Z, Chen Y et al (2020) Aerodynamic analysis of SARS-CoV-2 in two Wuhan hospital. Nature. https://doi. org/10.1038/s41586-020-2271-3

11. Workman AD, Welling DB, Carter BS et al (2020) Endonasal instrumentation and aerosolization risk in the era of COVID-19: simulation, literature review, and proposed mitigation strategies. Int Forum Allergy Rhinol. https://doi.org/10.1002/alr.22577

12. Sharma D, Rubel KE, Ye MJ et al (2020) Cadaveric simulation of endoscopic endonasal procedures: analysis of droplet splatter patterns during the COVID-19 pandemic. Otolaryngol Head Neck Surg. https://doi.org/10.1177/0194599820929274

13. Sharma D, Rubel KE, Ye MJ et al (2020) Cadaveric simulation of otologic procedures: an analysis of droplet splatter patterns during the COVID-19 pandemic. Otolaryngol Head Neck Surg. https:// doi.org/10.1177/0194599820930245

14. Poddubny VA, Luzhetskaya AP, Markelov YI et al (2012) Estimate of the urban effect on aerosol turbidity of the atmosphere according to data of two-point "background-industrial city" measurements. Atmos Ocean Opt 25:364-371. https://doi.org/10.1134/ S1024856012050089

15. Patel ZM, Fernandez-Miranda J, Hwang PH et al (2020) Letter: precautions for endoscopic transnasal skull base surgery during the COVID-19 pandemic. Neurosurgery 87(1):E66-E67. https:// doi.org/10.1093/neuros/nyaa125 
16. Bourouiba L (2020) Turbulent gas clouds and respiratory pathogen emissions: potential implications for reducing transmission of COVID-19. JAMA. https://doi.org/10.1001/jama.2020.4756

17. Philipp CM, Berlien HP (2003) Laser in der Oto-Rhino-Laryngologie. Physikalisch-medizinische Grundlagen [Lasers in otorhinolaryngology. Physical and medical principles]. Laryngorhinootologie. 82(Suppl 1):S1-S20. https://doi.org/10.1055/s-2003-38930

18. Kashima HK, Kessis T, Mounts P, Shah K (1991) Polymerase chain reaction identification of human papillomavirus DNA in $\mathrm{CO} 2$ laser plume from recurrent respiratory papillomatosis. Otolaryngol Head Neck Surg 104(2):191-195. https://doi. org/10.1177/019459989110400206

19. Sawchuk WS, Weber PJ, Lowy DR, Dzubow LM (1989) Infectious papillomavirus in the vapor of warts treated with carbon dioxide laser or electrocoagulation: detection and protection. J Am Acad Dermatol 21(1):41-49. https://doi.org/10.1016/s0190 -9622(89)70146-8

20. Gloster HM Jr, Roenigk RK (1995) Risk of acquiring human papillomavirus from the plume produced by the carbon dioxide laser in the treatment of warts. J Am Acad Dermatol 32(3):436-441. https://doi.org/10.1016/0190-9622(95)90065-9

21. Manson LT, Damrose EJ (2013) Does exposure to laser plume place the surgeon at high risk for acquiring clinical human papillomavirus infection? Laryngoscope 123(6):1319-1320. https:// doi.org/10.1002/lary.23642

22. Calero L, Brusis T (2003) Larynxpapillomatose - erstmalige Anerkennung als Berufskrankheit bei einer OP-Schwester [Laryngeal papillomatosis-first recognition in Germany as an occupational disease in an operating room nurse]. Laryngorhinootologie 82(11):790-793. https://doi.org/10.1055/s-2003-44546
23. Ishihama K, Sumioka S, Sakurada K, Kogo M (2010) Floating aerial blood mists in the operating room. J Hazard Mater 181(13):1179-1181. https://doi.org/10.1016/j.jhazmat.2010.05.110

24. David AP, Jiam NT, Reither JM et al (2020) Endoscopic skull base and transoral surgery during COVID-19 pandemic: minimizing droplet spread with negative-pressure otolaryngology viral isolation drape. Head Neck. https://doi.org/10.1002/hed.26239

25. Zou Y, Deng YQ, Xiao CW et al (2015) Comparison of outcomes between endoscopic surgery and conventional nasal packing for epistaxis in the posterior fornix of the inferior nasal meatus. Pak J Med Sci 31(6):1361-1365. https://doi.org/10.12669/ pjms. 316.8340

26. Shargorodsky J, Bleier BS, Holbrook EH et al (2013) Outcomes analysis in epistaxis management: development of a therapeutic algorithm. Otolaryngol Head Neck Surg 149(3):390-398. https:// doi.org/10.1177/0194599813492949

27. Brüske-Hohlfeld I, Preissler G, Jauch KW et al (2008) Surgical smoke and ultrafine particles. J Occup Med Toxicol. 3:31. https ://doi.org/10.1186/1745-6673-3-31

28. Wallace HC, Harries PG (2002) Epistaxis and conjunctival contamination-are our ENT trainees at risk? Ann R Coll Surg Engl 84(5):302-303. https://doi.org/10.1308/003588402760452574

Publisher's Note Springer Nature remains neutral with regard to jurisdictional claims in published maps and institutional affiliations. 